\title{
Novel metabolic biomarkers related to sulfur- dependent detoxification pathways in autistic patients of Saudi Arabia
}

\author{
Yusra A Al-Yafee ${ }^{1}$, Laila Y Al- Ayadhi, ${ }^{2,3,4}$, Samina H Haq ${ }^{1}$ and Afaf K El-Ansary ${ }^{1,2,3^{*}}$
}

\begin{abstract}
Background: Xenobiotics are neurotoxins that dramatically alter the health of the child. In addition, an inefficient detoxification system leads to oxidative stress, gut dysbiosis, and immune dysfunction. The consensus among physicians who treat autism with a biomedical approach is that those on the spectrum are burdened with oxidative stress and immune problems. In a trial to understand the role of detoxification in the etiology of autism, selected parameters related to sulfur-dependent detoxification mechanisms in plasma of autistic children from Saudi Arabia will be investigated compared to control subjects.
\end{abstract}

Methods: 20 males autistic children aged 3-15 years and 20 age and gender matching healthy children as control group were included in this study. Levels of reduced glutathione (GSH), total (GSH+GSSG), glutathione status (GSH/ GSSG), glutathione reductase (GR), glutathione- s-transferase (GST), thioredoxin (Trx), thioredoxin reductase (TrxR) and peroxidoxins (Prxs I and III) were determined.

Results: Reduced glutathione, total glutathione, GSH/GSSG and activity levels of GST were significantly lower, GR shows non-significant differences, while, Trx, TrxR and both Prx I and III recorded a remarkably higher values in autistics compared to control subjects.

Conclusion: The impaired glutathione status together with the elevated Trx and TrxR and the remarkable over expression of both Prx I and Prx III, could be used as diagnostic biomarkers of autism.

\section{Background}

Autism spectrum disorders (ASDs) are prevalent neurodevelopmental disorders that, based on a recent survey, affect not less than 1 in 150 children born [1]. Lastly, in Saudi Arabia (population under 23 million) there were 42500 confirmed cases of autism in 2002, and many more cases remain undiagnosed [2]. ASD diagnoses are characterized by impairments in social relatedness and communication, repetitive behaviours', abnormal movement patterns, and sensory dysfunction [3]. Further, common co-morbidity conditions often associated with an ASD diagnosis include gastrointestinal disease and dysbiosis [4], autoimmune disease [5], and mental retardation [6].

\footnotetext{
* Correspondence: elansary@ksu.edu.sa

'Biochemistry Department, Science College, King Saud University, P.O box 22452, Zip code11495, Riyadh, Saudi Arabia

Full list of author information is available at the end of the article
}

Several lines of evidence support an association of oxidative stress with ASD in at least some cases. First, there is evidence of reduced endogenous antioxidant capacity. Specifically, reduced enzymatic activities of glutathione peroxidase (GPX) [6-8], superoxide dismutase (SOD) $[7,8]$ and catalase $[9,10]$, and reduced levels of total glutathione (GSH), GSH/GSSG and cysteine [11] have been reported. Levels of exogenous antioxidants were also reportedly reduced in autism, including vitamin $\mathrm{C}$, vitamin $\mathrm{E}$ and vitamin $\mathrm{A}$ in plasma, and zinc and selenium in erythrocytes [12]. A second indicator of altered oxidative stress in autism is derived from evidence of impaired energy metabolism [13]. Magnetic resonance spectroscopic study of the brains of autistic individuals showed reduced synthesis of ATP [14]. In addition, higher lactate $[13,15,16]$ and pyruvate [17], levels have been reported. Third, there have been reports of improvement in certain behaviours following antioxidant administration to individuals with autism. In double-blind, placebo-controlled

\section{Biomed Central}


trials, high-dose vitamin C [18] or carnosine [19], improved autistic behaviour over baseline observations. Likewise, children with autism, who had decreased blood levels of the antioxidants GSH and cysteine as well as a decreased GSH/GSSG ratio compared with controls, had increases of these following a 3-week supplementation with betaine and folinic acid [11]. Fourth, increased excretion of oxidative stress biomarkers has been reported in children with autism. Specifically, the excretion of a F2 isoprostane, 8 isoprostaglandin F2a is increased in children with autism spectrum disorders [20]. This isoprostane is a product of nonenzymatic oxidation of arachidonic acid and is widely recognized as a reliable marker of lipid peroxidation [21]. Furthermore, nitric oxide, a free radical that can block energy production, was found to be increased in autism as compared to age and sex-matched controls [8]. In addition, elevated nitrite concentrations have been detected in individuals with autism along with elevations of thiobarbituric acid reactive substances and xanthine oxidase activity in red cells [22]. Consistent with the increased oxidative stress biomarkers, children with ASD were found to have increased body burdens of environmental toxins that may generate oxidative stress [23-26]. Taken together, these lines of evidence suggest that it is likely that at least some children with autism exhibit enhanced oxidative stress. However, none of these observations suggest how oxidative stress can lead to autism.

The formation of cross-links between the $\mathrm{SH}$ groups of cysteine amino acids to form disulfide bridges is an important process for maintaining the 3-dimensional structure of many proteins and enzymes. A cysteine thiol group is also the active site of some enzymes. Abnormally elevated thiols may possibly affect protein synthesis or enzyme function through disulfide bonding to the cysteinyl groups at structurally or enzymatically important sites, or by acting upon existing disulfide bridges. Elevated cysteine can interact with immunoglobulins and components of the complement pathway to reduce the clearance of immune complexes, a process which may be important in autoimmune-related diseases [27].

Such strong evidence of the contribution of oxidative stress in the aetiology of autism together with the highlighted role of the thiol redox couple in maintaining normal structure and function of many enzymatic and non-enzymatic antioxidant initiated our interest to measure glutathione and thioredoxin metabolism -related parameters in an attempt to understand how oxidative stress could lead to autism in a Saudi population.

\section{Methods}

\section{Subjects and methods}

The study protocol followed the ethical guidelines of the most recent Declaration of Helsinki (Edinburgh, 2000).
All subjects enrolled in the study had written informed consent provided by their parents and assented to participate if developmentally able. Subjects for this study were enrolled through the ART Center (Autism Research \& Treatment Center) clinic. The ART Center clinic sample population consisted of children diagnosed on the ASD. The diagnosis of ASD was confirmed in all subjects using the Autism Diagnostic Interview-Revised (ADI-R) and the Autism Diagnostic Observation Schedule (ADOS) and 3DI (Developmental, dimensional diagnostic interview). The ages of all autistic children range between 3 and 16 years old. All were males, non verbal. Intelligence quotient (IQ) for all autistic children was below 80. All were simplex cases. All are negative for fragile $\times$ gene study. The control group recruited from well baby clinic at king Khaled University Hospital and they were 3-16 year old. All participating subjects were excluded from the investigation if they had dismorphic features, tuberous sclerosis, angleman syndrome, or other serious neurological (e.g., seizures), psychiatric (e.g., bipolar disorder) or known medical conditions. All participants were screened via parental interview for current and past physical illness. Children with known endocrine, cardiovascular, pulmonary, liver, kidney or other medical disease were excluded from the study.

\section{Ethics approval and consent}

This work was ethically approved by the ethical committee of King Khalid Hospital, King Saud University (Approval number is $11 / 2890 /$ IRB). A written consent was obtained from the parents of each individual case, according to the guidelines of the ethical committee.

\section{Samples collection}

After overnight fast, $10 \mathrm{ml}$ blood samples were collected from both groups in test tubes containing heparin as anticoagulant. Centrifugation was done; plasma was obtained and deep frozen $\left(\right.$ at $\left.-80^{\circ} \mathrm{C}\right)$ until analysis time.

\section{Chemicals and kits}

All chemicals and kits used in this study were of analytical grade, a product of Sigma (USA), Biovision, Randox, or Northwest Company.

\section{Biochemical assays \\ Measurement of glutathione status}

Measurement of reduced GSH, total glutathione and GSH/GSSG ratio were assayed based on the glutathione recycling system by 5,5 -Dithio-bis (2-nitrobenzoic acid) (DTNB) and glutathione reductase.

\section{Determination of glutathione reductase activity (GR)}

GR was measured by following the reduction in the absorbance as NADPH converted to NADP at $340 \mathrm{~nm}$ during the reduction of GSSG to GSH [28]. 
Determination of glutathione-S-transferase activity (GST) The GST activity was assessed using (Biovision, USA) assay kit. Based upon that GST-catalysed reaction between GSH and the GST substrate, CDNB (1-chloro2, 4-dinitrobenzene). The GST-catalyzed formation of GS-DNB produces a dinitrophenyl thioether which can be detected by spectrophotometer at $340 \mathrm{~nm}$.

\section{Determination of thioredoxin reductase activity}

TR activity was measured using commercially available kit (Biovision, USA) according to the following principle:In the assay TR catalyzes the reduction of 5, 5'dithiobis (2-nitrobenzoic) acid (DTNB) with NADPH to 5-thio-2-nitrobenzoic acid (TNB2-), which generate a strong yellow color $(\lambda \max =412 \mathrm{~nm})$. Since in crude biological samples other enzymes, such as glutathione reductase and glutathione peroxidase, can also reduce DTNB, therefore, TR specific inhibitor is utilized to determine TR specific activity. Two assays were performed: the first measurement is of the total DTNB reduction by the sample, and the second one is the DTNB reduction by the sample in the presence of the TR specific inhibitor. The difference between the two results is the DTNB reduction by TR.

\section{Determination of Thioredoxin I level}

The Thioredoxin 1 ( $\operatorname{Tr} x 1)$ was assessed based on a sandwich Enzyme- Linked Immunosorbent Assay (ELISA) (product of northwest company). The microtiter plate provided has been pre-coated with a monoclonal antibody specific to human Trx1. This stationary phase antibody binds sample or standard Trx 1 while nonbound proteins are removed by washing. Next, bound Trx 1 is tagged with a biotin-conjugated monoclonal antibody specific for Trx1 followed by Avidin conjugated to Horseradish Peroxidase (HRP). Subsequent addition of TMB substrate solution causes blue color $(650 \mathrm{~nm})$ development proportional to the amount of $\operatorname{Trx} 1$ originally captured by the stationary phase antibody.

\section{Determination of Peroxiredoxin I and III levels}

The Peroxiredoxin 1(Prx1) and III (Prx3) were assessed based on a sandwich Enzyme- Linked Immunosorbent Assay (ELISA) (product of northwest company) similar to that used in thioredoxin level assay discussed previously with one exception. The microtiter plate provided has been pre-coated with a monoclonal antibody specific to human Prx1 or Prx 3 instead of Trx lantibody.

\section{Results}

Table 1 and figures 1A-I demonstrate the total glutathione, GSSG and GSH/GSSG in plasma of control and autistic children. It is clear from the table that these parameters recorded significantly impaired levels in autistic samples when compared to age - matching controls. Figure 1A represents the distribution of total GSH in autistic and control group. It could be easily observed

Table 1 Mean \pm S.D of all the measured parameters, percentage changes of autistic values relative to controls, and significant levels between both groups.

\begin{tabular}{|c|c|c|c|c|c|}
\hline Parameter & Group & $\mathbf{N}$ & Mean \pm S.D. & Percentage change & $P$ value \\
\hline \multirow[t]{2}{*}{ Total glutathione ( $\mu \mathrm{mol} / \mathrm{L})$} & Control & 20 & $8.28 \pm 1.03$ & 100.00 & 0.001 \\
\hline & Autistic & 20 & $4.46 \pm 0.33$ & 53.85 & \\
\hline \multirow[t]{2}{*}{ Oxidized glutathione (GSSG) ( $\mu \mathrm{mol} / \mathrm{L})$} & Control & 20 & $0.32 \pm 0.06$ & 100.00 & 0.001 \\
\hline & Autistic & 20 & $0.54 \pm 0.17$ & 170.84 & \\
\hline \multirow[t]{2}{*}{ GSH/GSSG } & Control & 20 & $26.07 \pm 5.03$ & 100.00 & 0.001 \\
\hline & Autistic & 20 & $8.03 \pm 2.46$ & 30.79 & \\
\hline \multirow[t]{2}{*}{ Glutathione reductase(U/L) } & Control & 20 & $60.19 \pm 15.42$ & 100.00 & 0.052 \\
\hline & Autistic & 20 & $70.25 \pm 16.35$ & 116.71 & \\
\hline \multirow[t]{2}{*}{ Glutathione $S$ transferase $(\mu \mathrm{mol} / \mathrm{min} / \mathrm{ml})$} & Control & 20 & $0.73 \pm 0.37$ & 100.00 & 0.002 \\
\hline & Autistic & 20 & $0.42 \pm 0.18$ & 57.48 & \\
\hline \multirow[t]{2}{*}{ Peroxiredoxin 1 (ng/ml) } & Control & 20 & $20.25 \pm 5.99$ & 100.00 & 0.001 \\
\hline & Autistic & 20 & $40.75 \pm 17.92$ & 201.23 & \\
\hline \multirow[t]{2}{*}{ Peroxiredoxin 3 (ng/ml) } & Control & 20 & $24.30 \pm 2.69$ & 100.00 & 0.001 \\
\hline & Autistic & 20 & $43.05 \pm 5.86$ & 177.16 & \\
\hline \multirow[t]{2}{*}{ Thioredoxin 1 (ng/ml) } & Control & 20 & $44.71 \pm 7.43$ & 100.00 & 0.001 \\
\hline & Autistic & 20 & $74.70 \pm 9.04$ & 167.09 & \\
\hline \multirow[t]{2}{*}{ Thioredoxin reductase $(\mathrm{mU} / \mathrm{ml})$} & Control & 20 & $1.83 \pm 0.52$ & 100.00 & 0.001 \\
\hline & Autistic & 20 & $3.37 \pm 1.22$ & 184.15 & \\
\hline
\end{tabular}

Independent student's t-test between the control and autistic groups and percentage change in total glutathione level, oxidised glutathione (GSSG), GSH/GSSG, glutathione reductase, glutathione -S- transferase, peroxiredoxin 1, peroxiredoxin 3 level, thioredoxin 1, thioredoxin reductase (mU/ml). 


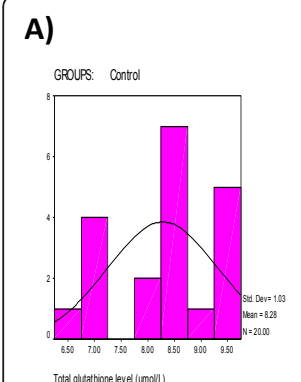

D)

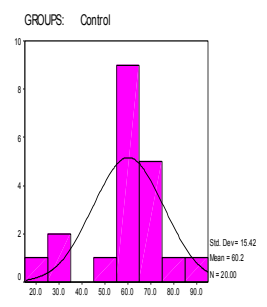

G)

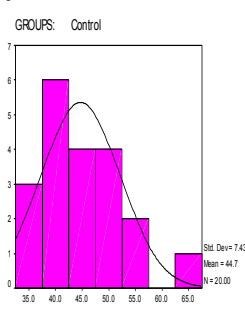

Thibestoxin 1 kvel (logim)

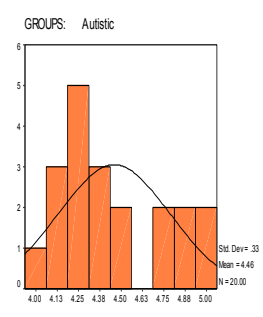

Total gutatione level (Mmoll)

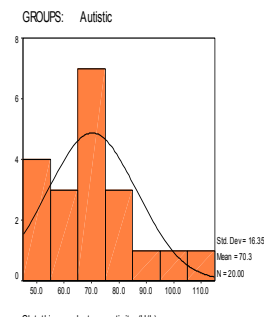

Gutathione restuclase ectiviny (UIL)

GRoups: Autistic

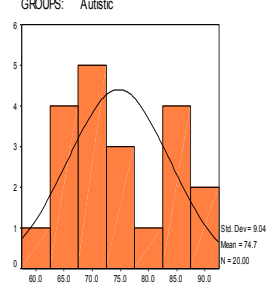

Thioredoxin 1 level (ngim)
B)

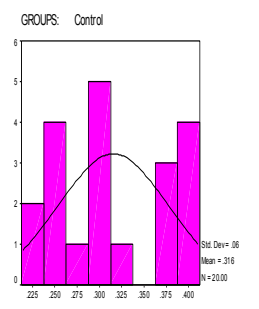

E)

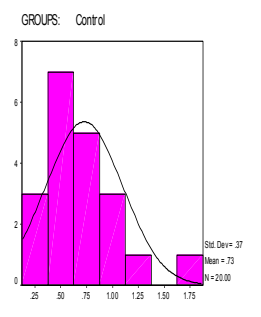

H)

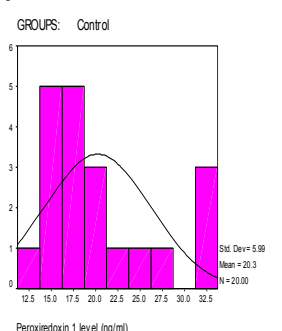

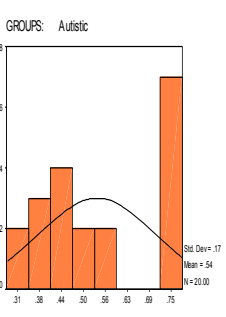

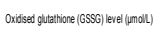
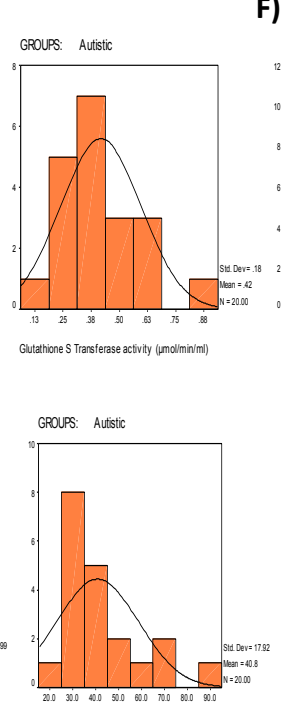

Peroxietedxini 1 kvel (rogrm)
C)

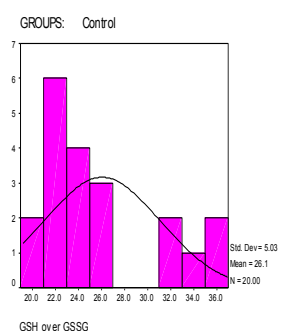

F)

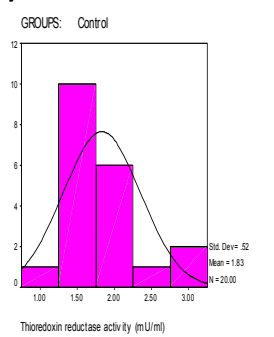

I)

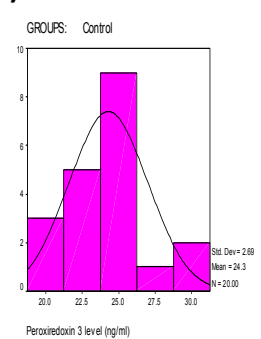

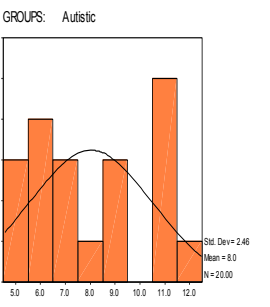

GSH over GSSG

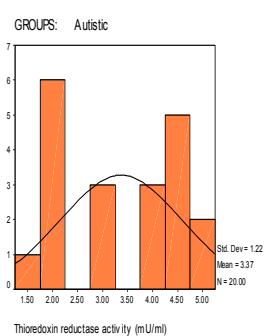

Thiberobxin reductasse accivity (mUUm)

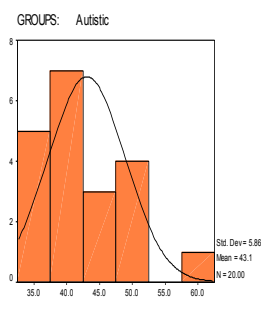

Peroxiedeoxin 3 kevel ingyml)

Figure 1 Normal distribution of the measured parameters in plasma of control and autistic patients.

that $20 / 20$ of the autistic children have total GSH level values in $(\mu \mathrm{mole} / \mathrm{L})$ lower than the minimum value recorded in control group. Autistic children recorded a remarkable percentage decrease $(-46.15 \%)$ compared to age-matching control. Moreover while GSSG shows remarkable higher values in autistics, recording 70\% increase, GSH/GSSG ratio was significantly lower, with percentage decrease of $(-70 \%)$ relative to control. Distribution of these two parameters confirmed their altered values in most of the studied autistic subjects (Figure 1B $\& 1 C)$.

The significant reduction in plasma glutathione $\mathrm{s}$ transferase activity in autistic patients compared to control $(-42.52 \%)$ is shown in the graphical distribution demonstrated in Figure 1E. 10/20 of control subject recorded value of $0.75(\mu \mathrm{mol} / \mathrm{min} / \mathrm{ml})$ or higher compared to $19 / 20$ of autistic subjects that recorded lower values.

Table 1 together with Figure 1F show an obvious significant elevation on thioredoxin reductase activity in autistic patients $(84.15 \%)$ compared to age and sex matching control. Results shows that 20/20 of control subject record enzymatic activity equal to $3(\mathrm{mU} / \mathrm{ml})$ or lower compared to only half of the autistic participants recorded this values. Moreover, results represented in table 1 and Figure $1 \mathrm{G}$ demonstrate the levels of thioredoxin in plasma of control and autistic children. It could be easily noticed from the table that this parameter recorded significantly raised levels in autistic samples when compared to age - matching controls. Graphical distribution of Trx in autistic and control groups show that $20 / 20$ of the autistic children have Trx levels range between $59.93-89.7 \mathrm{ng} / \mathrm{ml}$ while only $1 / 20$ of the control samples recorded values within this range. Autistic children recorded a high percentage increase (67.09\%) compared to age-matching control.

Tables 1 and Figures $1 \mathrm{H}$ \&I demonstrate the peroxiredoxin I and III levels in control and autistic subjects. It could be easily noticed that prx I and prx III levels are significantly higher in autistic patients compared to control. Prx I shows almost 3 folds higher values with high percentage increase (101.23\%) compared to control. In case of prx III levels the highest value recorded in control subjects was less than the lowest value recorded in autistic patients with no observed overlapping between the two groups. 
Table 2 Pearson correlation test showing correlation significance differences between the different measured parameters:

\begin{tabular}{|c|c|c|c|}
\hline Parameters & Pearson Correlation & Sig. & \\
\hline Total glutathione GSSG & -0.536 & 0.000 & $\mathrm{~N}^{\mathrm{b}}$ \\
\hline Total glutathione level $\sim$ Glutathione reductase & -0.339 & 0.032 & $\mathrm{~N}^{\mathrm{b}}$ \\
\hline Total glutathione $\sim$ Glutathione S Transferase & 0.502 & 0.001 & $\mathrm{P}^{a}$ \\
\hline Total glutathione $\sim$ Peroxiredoxin 1 & -0.553 & 0.000 & $\mathrm{~N}^{\mathrm{b}}$ \\
\hline Total glutathione $\sim$ peroxiredoxin 3 & -0.861 & 0.000 & $\mathrm{~N}^{\mathrm{b}}$ \\
\hline Total glutathione $\sim$ thioredoxin 1 & -0.800 & 0.000 & $\mathrm{~N}^{\mathrm{b}}$ \\
\hline Total glutathione $\sim$ thioredoxin reductase & -0.550 & 0.000 & $\mathrm{~N}^{\mathrm{b}}$ \\
\hline Total glutathione $\sim$ GSH/GSSG & 0.871 & 0.000 & $\mathrm{P}^{a}$ \\
\hline GSSG glutathione S Transferase & -0.436 & 0.005 & $\mathrm{~N}^{\mathrm{b}}$ \\
\hline GSSG $\sim$ peroxiredoxin 3 & 0.543 & 0.000 & $\mathrm{P}^{\mathrm{a}}$ \\
\hline GSSG $\sim$ thioredoxin 1 & 0.602 & 0.000 & $\mathrm{P}^{\mathrm{a}}$ \\
\hline GSSG $\sim$ thioredoxin reductase & 0.447 & 0.004 & $\mathrm{P}^{a}$ \\
\hline GSSG GSH/GSSG & -0.801 & 0.000 & $\mathrm{~N}^{\mathrm{b}}$ \\
\hline Glutathione reductase) $\sim$ peroxiredoxin 1 & 0.464 & 0.003 & $\mathrm{P}^{\mathrm{a}}$ \\
\hline Glutathione $\mathrm{S}$ transferase $\sim$ peroxiredoxin 3 & -0.364 & 0.021 & $\mathrm{~N}^{\mathrm{b}}$ \\
\hline Glutathione S Transferase $\sim$ thioredoxin 1 & -0.434 & 0.005 & $\mathrm{~N}^{\mathrm{b}}$ \\
\hline Glutathione S Transferase $\sim$ thioredoxin reductase & -0.494 & 0.001 & $\mathrm{~N}^{\mathrm{b}}$ \\
\hline Glutathione S Transferase $\sim$ GSH/GSSG & 0.513 & 0.001 & $\mathrm{P}^{\mathrm{a}}$ \\
\hline Peroxiredoxin $1 \sim$ Peroxiredoxin 3 & 0.519 & 0.001 & $\mathrm{P}^{\mathrm{a}}$ \\
\hline Peroxiredoxin $1 \sim$ thioredoxin 1 & 0.517 & 0.001 & $\mathrm{P}^{\mathrm{a}}$ \\
\hline Peroxiredoxin $1 \sim$ thioredoxin reductase & 0.446 & 0.004 & $\mathrm{P}^{a}$ \\
\hline Peroxiredoxin $1 \sim$ GSH/GSSG & -0.525 & 0.001 & $\mathrm{~N}^{\mathrm{b}}$ \\
\hline Peroxiredoxin $3 \sim$ thioredoxin 1 & 0.873 & 0.000 & $\mathrm{P}^{a}$ \\
\hline Peroxiredoxin $3 \sim$ thioredoxin reductase & 0.617 & 0.000 & $P^{a}$ \\
\hline Peroxiredoxin $3 \sim$ GSH/GSSG & -0.803 & 0.000 & $\mathrm{~N}^{\mathrm{b}}$ \\
\hline Thioredoxin $1 \sim$ thioredoxin reductase & 0.615 & 0.000 & $\mathrm{P}^{\mathrm{a}}$ \\
\hline Thioredoxin $1 \sim$ GSH/GSSG & -0.779 & 0.000 & $\mathrm{~N}^{\mathrm{b}}$ \\
\hline Thioredoxin reductase $\sim$ GSH/GSSG & -0.558 & 0.000 & $\mathrm{~N}^{\mathrm{b}}$ \\
\hline
\end{tabular}

\footnotetext{
a Positive Correlation.
}

${ }^{\mathrm{b}}$ Negative Correlation.

Table 2 and Figure 2 demonstrate Pearson correlations between all the measured parameters. It could be easily noticed that most of the measured parameters are either positively or negatively correlated with different levels of significance. Only those which demonstrate the most significant correlations between glutathione in one hand and thioredoxin- related parameters in the other hand are presented in Figure 3.

Table 3 and Figure 3 demonstrate the receiver operating characteristics of the measured parameters. Area under the curve, specificity and sensitivity of the measured parameters are illustrated

\section{Discussion}

Clinical and preclinical investigations of the actions of antioxidative defence systems in the brain suggest several ways in which ongoing oxidative stress as a primary phenomenon might impact the occurrence and severity of autism [11]. Mitochondrial dysfunction, leaky blood brain barrier, higher levels of circulating cytokines and autoimmune response to brain antigen may be promoted by oxidative generation of neoepitopes, which occurs via oxidative alteration of neurodevelopmental proteins [29-31].

All cellular functions are affected by the prevailing redox status, and sulfur metabolism plays a central role in maintaining a redox potential that is favorable for homeostasis. In the present study, the significantly decreased plasma total GSH levels (table 1 and Figure 1A) among the participants diagnosed with autism is of concern. GSH is a tripeptide of cysteine, glycine, and glutamate that is synthesized in every cell of the body. The essential intracellular reducing environment is maintained by the high ratio of reduced GSH/GSSG [32]. The 


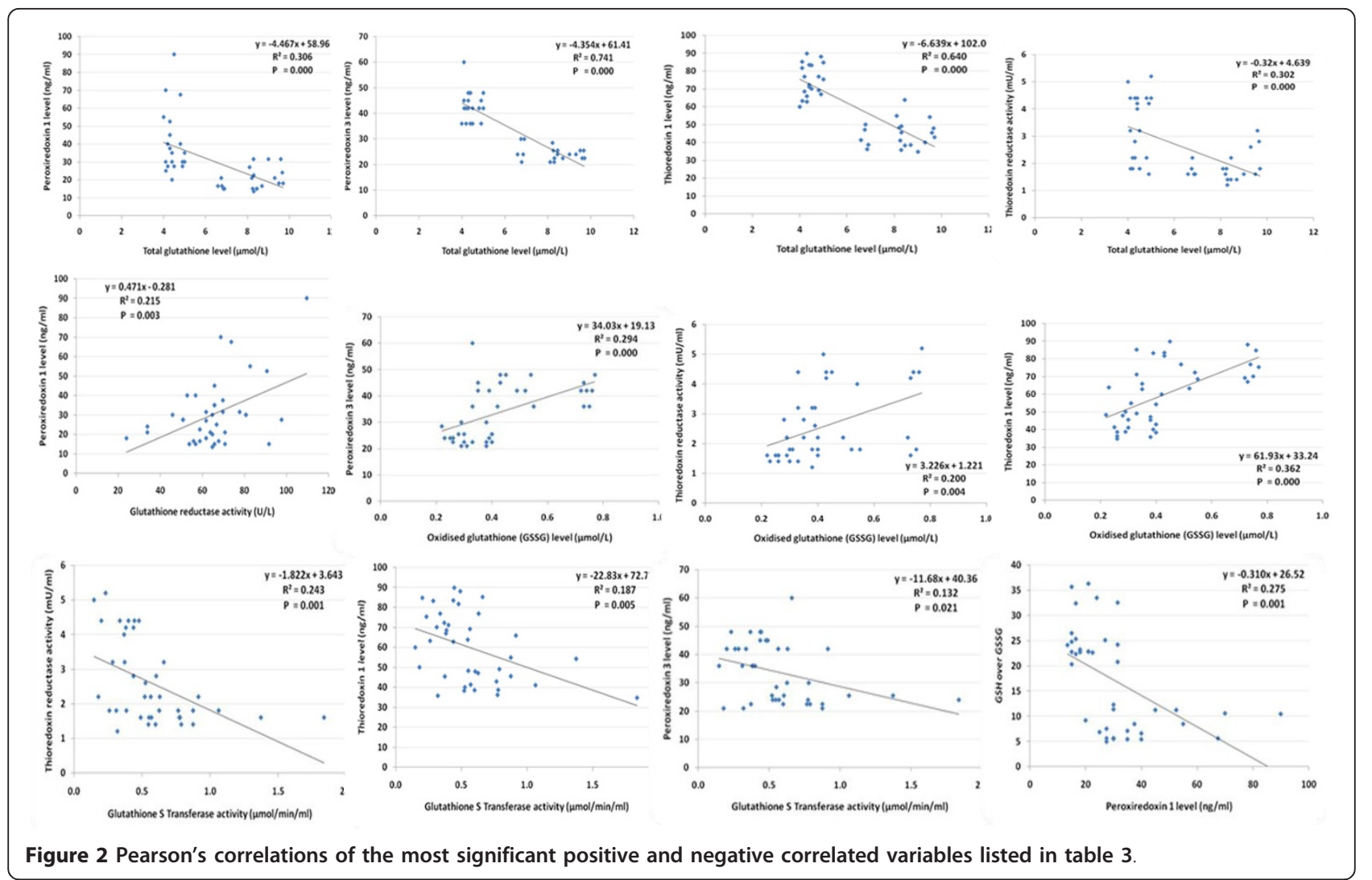

GSH redox equilibrium regulates a wide range of functions that include nitrogen and oxygen free radical scavenger [33], protein redox status and enzyme activity [34], cell membrane integrity and signal transduction $[35,36]$, transcription factor binding and gene expression [37], phase II detoxification [38], and apoptosis [39]. The observed depletion of total GSH could be supported through considering the recent reports which also demonstrate that, compared to controls, patients with autism showed reduced levels of plasma total glutathione

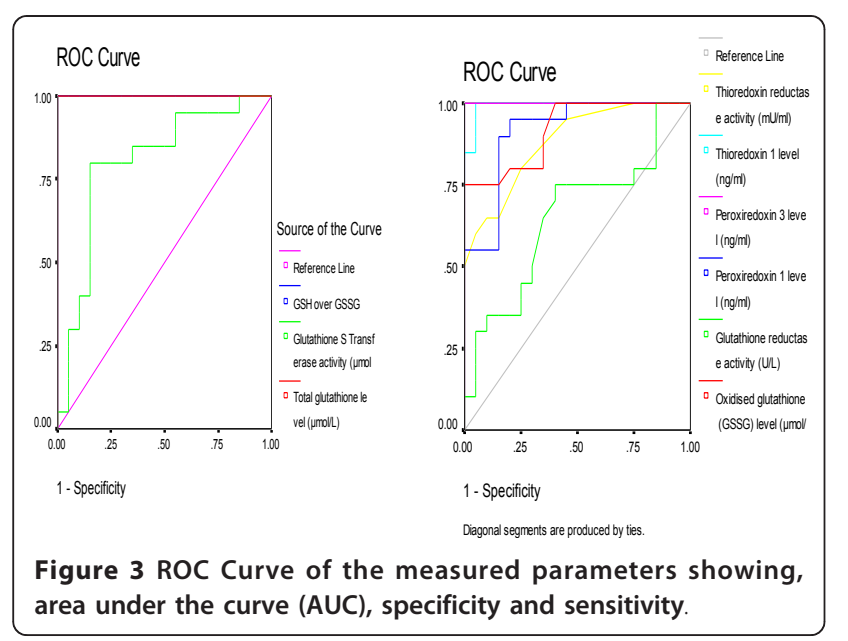

$[40,41]$. Oxidative stress caused by GSH depletion may also play a role in the increased male to female ratio observed in autism. Because of lower levels of reduced glutathione, mitochondria from males, when compared to females, are more vulnerable to oxidative stress [42]. In animal studies, due to lower enzyme activity levels of superoxide dismutase (SOD) and glutathione peroxidase in males, oxidative damage to mitochondrial DNA is 4fold higher in males compared to females [43]. The obtained higher GSSG levels as a reliable marker of intracellular oxidative stress in autistics (table 1 and Figure 1B) could find a support in the previous work of James et al., 2004 [12] who recorded 72\% higher GSSG in children with autism when compared to neurotypical children.

The unexpected, non-significant change in the activity of glutathione reductase in autistic children when compared to normal controls (table 1 and Figure 1D) could be explained on the basis that under physiological conditions, glutathione reductase activity is sufficient to maintain an elevated reduced/oxidized glutathione ratio. However, excessive intracellular oxidative stress, exceeding the capacity of glutathione reductase will induce export of GSSG to the plasma in an attempt to regain intracellular redox homeostasis [44].

The significant reduction in plasma glutathione -Stransferase in plasma of autistic patients compared to 
Table 3 ROC analysis of the measured parameters showing area under the curve,cutoff values, sensitivity and specificity.

\begin{tabular}{|c|c|c|c|c|}
\hline Parameter & Area under the curve & Cutoff value & Sensitivity $\%$ & Specificity $\%$ \\
\hline Total glutathione & 1.000 & 9.320 & $100.0 \%$ & $20.0 \%$ \\
\hline Oxidised glutathione (GSSG) & 0.919 & 0.380 & $80.0 \%$ & $80.0 \%$ \\
\hline GSH/GSSG & 1.000 & 31.100 & $100.0 \%$ & $20.0 \%$ \\
\hline Glutathione reductase & 0.650 & 75.620 & $30.0 \%$ & $90.0 \%$ \\
\hline Glutathione- S- transferase & 0.803 & 1.100 & $100.0 \%$ & $15.0 \%$ \\
\hline Peroxiredoxin 1 & 0.915 & 26.240 & $90.0 \%$ & $80.0 \%$ \\
\hline Peroxiredoxin 3 & 1.000 & 26.990 & $100.0 \%$ & $85.0 \%$ \\
\hline Thioredoxin 1 & 0.993 & 52.140 & $100.0 \%$ & $85.0 \%$ \\
\hline Thioredoxin reductase & 0.881 & 2.350 & $65.0 \%$ & $85.0 \%$ \\
\hline
\end{tabular}

control subjects (table 1 and Figure 1E) could be easily correlated to lack of substrate availability in autistic subjects i.e. reduced glutathione (GSH) that was previously observed in autistic patients $[11,40,41]$. The recorded reduction in this essential detoxifying enzyme could explain the observed poor detoxification power in autistic patients, such as in case of mercury or lead toxicity $[25,26,44]$. The lower activity levels of glutathione-Stransferase, reported in the present study is in good agreement with the previous study done by Hung et al [45] in which they proved that Glutathione-S-transferase activity was reduced in autistic patients compared to control. Moreover it could find a support in a genetic study on this enzyme which revealed that M1 (GSTM1), is reduced or absent in individuals carrying the GSTM1*0 (null) allele, increasing their sensitivity to xenobiotics [46] In addition, two recent studies have reported an association between the null allele and autism suggesting that GST contributes to the risk of oxidative stress and autism [46,47].

The key biological activities of Trx that are applicable to human disease can be categorized as antioxidant, growth promoting, anti-apoptotic and inflammation modulating [48]. Beyond its protective role, the Txn system is involved in various cellular processes, such as cell-cell communication, transcriptional regulation, cell signalling, and DNA synthesis [49]. Any particular biological property of thioredoxin $(\operatorname{Trx})$ is unlikely to be either 'good' or 'bad' in human diseases [50]. Over expression of TrxR as a major antioxidant enzyme, recorded in the present study could support the hypothesis stated that oxidative stress is linked with the etiology of autism $[11,47]$. One of the most important roles of the Trx/TrxR system is to maintain reduced redox status and prevent oxidative stress. This function is holding up mainly by the peroxiredoxin system. Recently Drechsel and Patel [51] demonstrate that Trx/Prx is the major contributing enzyme system to respiration-dependent $\mathrm{H}_{2} \mathrm{O}_{2}$ removal in brain mitochondria, while GSH/
GPx and non-enzymatic systems show only minor contributions. This pathway could be easily followed in Figure 4.

For all of that, in this study we also measured different Prx levels to obtain their assumed role in autism. The demonstrated over expression of both Prx I and Prx III as biomarkers of oxidative stress in autistic patients compared to age and gender-matching control subjects (table 1 and Figure 1H \&1I), could support their roles in the pathology of autism. Besides their cytoprotective antioxidant function, Prxs appeared to play an important role in cell proliferation, differentiation, immune response, protection of oxidant-sensitive proteins, regulation of cellular $\mathrm{H}_{2} \mathrm{O}_{2}$ and control of apoptosis, processes involving a redox signalling [52]. Prx3 overexpression alters the mitochondrial membrane potential, reduces endogenous cellular $\mathrm{H}_{2} \mathrm{O}_{2}$ levels. The results of Nonn et al [53] suggested that mitochondrial Prx3 is an important regulator of $\mathrm{H}_{2} \mathrm{O}_{2}$ in the cell. They reported that, at low physiological levels of $\mathrm{H}_{2} \mathrm{O}_{2}$, Prx3 inhibits the growth-stimulating effects of $\mathrm{H}_{2} \mathrm{O}_{2}$, while at

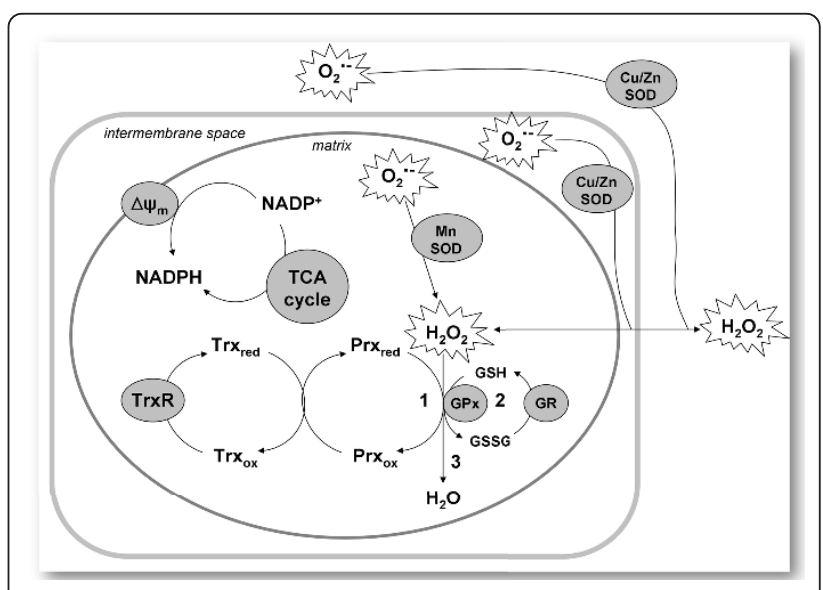

Figure 4 Proposed model of $\mathrm{H} 2 \mathrm{O} 2$ removal in brain mitochondria[51]. 
higher levels of $\mathrm{H}_{2} \mathrm{O}_{2}$ generation; Prx3 protects cells against apoptosis [54].

Based on this information, the recorded raised levels of Trx, TrxR and Prxs of the present study could be related to the previous work of Al-Gadani et al [11] in which they proved that Saudi autistic children are under $\mathrm{H}_{2} \mathrm{O}_{2}$ stress due to over expression of SOD and a slightly lower activity of catalase.

The lack of satisfactory specificity values in glutathione-related parameters could be supported through considering the facts that glutathione system is known to be altered in many chronic neurological disorders [11,54-56].

\section{Conclusion}

The satisfactory high values of both sensitivity and specificity recorded by Trx, TrxR and Prxs could help to suggest them as biomarkers for the diagnosis of autism in Saudi population. Based on this study which confirmed the impaired antioxidant status in Saudi autistics, early intervention through supplementation of perfect and safe antioxidants as omega-3, carnosine, selenium and others could be helpful because no doubt that autistic children who undergo intensive intervention, be it behavioural or developmental, do better than children who don't.

\section{Abbreviations}

ART: Autism Research and Treatment centre; ASD: Autism Spectrum Disorder; IQ: Intelligence quotient; GSH: reduced glutathione; GSH+GSSG: total glutathione; GSH/GSSG: glutathione status; GR: glutathione reductase; GST: glutathione- s-transferase; Trx: thioredoxin; TrxR: thioredoxin reductase (TrxR); Prxs I and III: peroxidoxins I and III; $\mathrm{H}_{2} \mathrm{O}_{2}$ : hydrogen peroxide; DNA: deoxyribonucleic acid.

\section{Acknowledgments}

This research project was supported by a grant from the research center of the center for female scientific and medical colleges in King Saud University. The authors extend their appreciation to King Abdul-Aziz City for Science and Technology (KACST) for co-funding the work.

\section{Author details \\ ${ }^{1}$ Biochemistry Department, Science College, King Saud University, P.O box 22452, Zip code11495, Riyadh, Saudi Arabia. ${ }^{2}$ Autism Research and Treatment Center, Riyadh, Saudi Arabia. ${ }^{3}$ Shaik AL-Amodi Autism Research Chair, King Saud University, Riyadh, Saudi Arabia. ${ }^{4}$ Department of Physiology, Faculty of Medicine, King Saud University, Riyadh, Saudi Arabia.}

\section{Authors' contributions}

YA: Carried out the biochemical assays, LA: Confirmed the diagnosis, provided the samples and ethical approval, $\mathbf{S H}$ : Participated in performing the statistical analysis, AE: Designed the study and drafted the manuscript. All authors have read and approved the final manuscript.

\section{Competing interests}

The authors declare that they have no competing interests.

Received: 8 July 2011 Accepted: 4 November 2011 Published: 4 November 2011
References

1. Eigsti IM, Shapiro T: A systems neuroscience approach to autism: biological, cognitive, and clinical perspectives. Ment Retard Dev Disabil Res Rev 2003, 9:205-15.

2. , BMJ 328:226 doi: 10.1136/bmj.328.7433.226-c (published 22 January 2004).

3. White JF: Intestinal pathophysiology in autism. Exp Biol Med 2003, 228:639-49.

4. Buie T, Campbell DB, Fuchs GJ, Furuta GT, Levy J, Vandewater J, et al: Evaluation, diagnosis, and treatment of gastrointestinal disorders in individuals with ASDs: A consensus report. Pediatrics 2010, 125(Suppl 1): S1-S18.

5. Sweeten $T L$, Bowyer SL, Posey DJ, Halberstadt CM, McDougle CJ: Increased prevalence of familial autoimmunity in probands with pervasive developmental disorders. Pediatrics 2003, 112:420.

6. Bolte S, Poustka F: The relation between general cognitive level and adaptive behavior domains in individuals with autism with and without co-morbid mental retardation. Child Psychiatry Hum Dev 2002, 33:165-72.

7. Golse B, Debray-Ritzen P, Durosay P, Puget K, Michelson AM: Alterations in two enzymes: superoxide dismutase and glutathione peroxidase in developmental infantile psychosis (infantile autism). Rev Neurol (Paris) 1978, 134:699-705

8. Sogut S, Zoroglu SS, Ozyurt H, Yilmaz HR, Ozugurlu F, Sivasli E: Changes in nitric oxide levels and antioxidant enzyme activities may have a role in the pathophysiological mechanisms involved in autism. Clin Chim Acta 2003, 331:111-7.

9. Yorbik O, Sayal A, Akay C, Akbiyik DI, Sohmen T: Investigation of antioxidant enzymes in children with autistic disorder. Prostaglandins Leukot Essent Fatty Acids 2002, 67:341-3.

10. Zoroglu SS, Armutcu F, Ozen S, Gurel A, Sivasli E, Yetkin O, et al: Increased oxidative stress and altered activities of erythrocyte free radical scavenging enzymes in autism. Eur Arch Psychiatry Clin Neurosci 2004, 254:143-7

11. Al-Gadani Y, Al-Ansary A, Al-Attas O, Al-Ayadhi L: Oxidative stress and antioxidant status in Saudi autistic children. Clin. Biochemistry 2009, 24:1032-1040.

12. James SJ, Cutler P, Melnyk S, Jernigan S, Janak L, Gaylor DW, et al: Metabolic biomarkers of increased oxidative stress and impaired methylation capacity in children with autism. Am J Clin Nutr 2004, 80:1611-7

13. Al-Mosalem O, Al-Ansary A, Al-Attas O, Al-Ayadhi L: Metabolic biomarkers related to energy metabolism in Saudi autistic children. Clin Biochem 2009, 42:949-957.

14. Minshew NJ, Goldstein G, Dombrowski SM, Panchalingam K, Pettegrew JW: A preliminary 31P MRS study of autism: evidence for undersynthesis and increased degradation of brain membranes. Biol Psychiatry 1993, 33:762-73.

15. Minshew NJ, Goldstein G, Dombrowski SM, Panchalingam K, Pettegrew JW: A preliminary 31P MRS study of autism: evidence for undersynthesis and increased degradation of brain membranes. Biol Psychiatry 1993, 33:762-73.

16. Chugani D, Sundram B, Behen M, Lee M, Moore G: Evidence of altered energy metabolism in autistic children, Prog. Neuropsychopharmacol Biol Psychiatry 1999, 23:635-641.

17. Moreno H, Borjas L, Arrieta A, Saez L, Prassad A, Estevez J, et al: Clinical heterogeneity of the autistic syndrome: a study of 60 families. Invest Clin 1992, 33:13-31.

18. Dolske MC, Spollen J, McKay S, Lancashire E, Tolbert L: A preliminary trial of ascorbic acid as supplemental therapy for autism. Prog Neuropsychopharmacol Biol Psychiatry 1993, 17:765-74.

19. Chez MG, Buchanan CP, Aimonovitch MC, Becker M, Schaefer K, Black C, et al: Double-blind, placebo-controlled study of L-carnosine supplementation in children with autistic spectrum disorders. J Child Neurol 2002, 17:833-7.

20. Ming X, Stein TP, Brimacombe M, Johnson WG, Lambert GH, Wagner GC: Increased excretion of a lipid peroxidation biomarker in autism. Prostaglandins Leukot Essent Fatty Acids 2005, 73:379-84.

21. Montuschi $P$, Barnes PJ, Roberts $L$ : Isoprostanes: markers and mediators of oxidative stress. FASEB J 2004, 18:1791-800.

22. Zoroglu SS, Yurekli M, Meram I, Sogut S, Tutkun H, Yetkin O, et al: Pathophysiological role of nitric oxide and adrenomedullin in autism. Cell Biochem Funct 2003, 21:55-60. 
23. Edelson SB, Cantor DS: The neurotoxic etiology of the autistic spectrum disorder: a replicative study. Toxicol Ind H 2000, 16:239-47.

24. Edelson SB, Cantor DS: Autism: xenobiotic influences. Toxicol Ind Health 1998, 14:799-811.

25. El-Ansary A, Al-Daihan S, Al-Dbass A, Al-Ayadhi L: Measurement of selected ions related to oxidative stress and energy metabolism in Saudi autistic children. Clin Biochem 2010, 43(1-2):63-70.

26. El-Ansary AK, Ben Bacha AG, Al-Ayadhi LY: Plasma fatty acids as diagnostic markers in autistic patients from Saudi Arabia. Lipids Health Dis 2011, 10(1):62..

27. Bradley H, Gough A, Sokhi RS, Hassell A, Waring R, Emery P: Sulfate metabolism is abnormal in patients with rheumatoid arthritis. Confirmation by in vivo biochemical findings. J Rheumatol 1994, 21:1192-1 196

28. Spooner RJ, Delides A, Goldberg DM: Heat stability and kinetic properties of human serum glutathione reductase activity in various disease states. Biochem Med 1981, 26(2):239-48.

29. Singh VK, Warren RP, Odell JD, et al: Antibodies to myelin basic protein in children with autistic behavior. Brain Behav Immun 1993, 7:97-103.

30. Singh VK: Plasma increase of interleukin-12 and interferon-gamma: Pathological significance in autism. Journal of Neuroimmunology 1996, 66:143-145.

31. Molloy CA, Morrow AL, Meinzen-Derr J, Schleifer K, Dienger K, ManningCourtney P, Altaye M, Wills-Karp M: Elevated cytokine levels in children with autism spectrum disorder. Journal of Neuroimmunology 2006, 172:198-205.

32. Schafer FQ, Buettner GR: Redox environment of the cell as viewed through the redox state of the glutathione disulfide/glutathione couple. Free Radic Biol Med 2001, 30(11):1191-212.

33. Chugani DC, Sundram BS, Behen M, Lee ML, Moore GJ: Evidence of altered energy metabolism in autistic children. Prog Neuropsychopharmacol Biol Psychiatry 1999, 23:635-41.

34. Klatt P, Lamas S: Regulation of protein function by S-glutathiolation in response to oxidative and nitrosative stress. Eur J Biochem 2000, 267(16):4928-44.

35. Ji L, Liu R, Zhang XD, Chen HL, Bai H, Wang X, Zhao HL, Liang X, Hai CX: Nacetylcysteine attenuates phosgene-induced acute lung injury via upregulation of Nrf2 expression. Inhal Toxicol 2010, 22(7):535-42.

36. Sagrista ML, Garcia AF, Africa De Madariaga M, Mora M: Antioxidant and pro oxidant effect of the thiolic compounds $\mathrm{N}$-acetyl-L-cysteine and glutathione against free radical-induced lipid peroxidation. Free Radical Research 2002, 36:329-340.

37. Deplancke B, Gaskins HR: Redox control of the transsulfuration and glutathione biosynthesis pathways. Current Opinion in Clinical Nutrition and Metabolic Care 2002, 5:85-92.

38. Pastore A, Federici G, Bertini E, Piemonte E: Analysis of glutathione: Implication in redox and detoxification. Clinica Chimica Acta 2003, 333:19-39.

39. Hall AG: The role of glutathione in the regulation of apoptosis. European Journal of Clinical Investigation 1999, 29:238-245.

40. Geier DA, Ken JK, Graver CR, Adams JB: Biomarkers of environmental toxicity and susceptibility in autism. Neural Sci 2008, 6:431-561.

41. Vojdani A, Bock K, Hirani AK: Low natural killer cell cytotoxic activity in autism: the role of glutathion, IL-2 and IL-15. J Neuroimmunal 2008, 205:148-154.

42. Viña J, Sastre J, Pallardó F, Borrás C: Mitochondrial theory of aging: importance to explain why females live longer than males. Antioxid Redox Signal 2003, 5(5):549-56.

43. Palmieri L, Persico AM: Mitochondrial dysfunction in autism spectrum disorders: Cause or effect? Biochimica et Biophysica Acta (BBA) Bioenergetics 2010, 1797(6-7):1130-1137.

44. Mutter J, Naumann J, Schneider R, Walach H, Haley B: Mercury and autism: accelerating evidence? Neuroendocrinology Letters 2004, 26:439-446.

45. Hung RG, Boffetta P, Brennan C, Malaveille A, Donato F: GST, NAT, SULT1A1, CYP1B1 genetic polymorphisms, interactions with environmental exposures and bladder cancer risk in a high-risk population. Int J Cancer 2004, 110:4598-4604.

46. Buyske S, Williams TA, Mars AE, Stenroos ES, Ming SX, Wang R, Sreenath M, Factura MF, Reddy C, Lambert GH, Johnson WG: Analysis of case-parent trios at a locus with a deletion allele: association of GSTM1 with autism. BMC Genet 2006, 10:8.
47. James SJ, Melnyk S, Jernigan S, Cleves MA, Halsted CH, Wong DH, Cutler P, Bock K, Boris M, Bradstreet JJ, Baker SM, Gaylor DW: Metabolic endophenotype and related genotypes are associated with oxidative stress in children with autism. Am J Med Genet B Neuropsychiatr Genet 2006, 141:947-956.

48. Watson WH, Pohl J, Montfort WR, Stuchlik O, Reed MS, Powis G, Jones DP: Redox potential of human thioredoxin 1 and identification of a second dithiol/disulfide motif.". J Biol Chem 2003, , 278: 33408-33415.

49. Lillig $\mathrm{CH}$, Holmgren $\mathrm{A}$ : Thioredoxin and related molecules-from biology to health and disease. Antioxid Redox Signal 2007, 9:25-47.

50. Masutani $\mathrm{H}$, et al: Thioredoxin as a neurotrophic cofactor and an important regulator of neuroprotection. Mol Neurobiol 2004, 29:229-242.

51. Drechsel DA, Patel M: Respiration-dependent $\mathrm{H}_{2} \mathrm{O}_{2}$ removal in brain mitochondria via the thioredoxin/peroxiredoxin system. J Biol Chem 2010, 285(36):27850-8.

52. Rhee SG, Chae HZ, Kim K: Peroxiredoxins: a historical overview and speculative preview of novel mechanisms and emerging concepts in cell signaling. Free Rad Biol Med 2005, 38:1543-1552.

53. Nonn L, Berggren M, Powis G: Increased Expression of Mitochondrial Peroxiredoxin-3(Thioredoxin Peroxidase-2) Protects Cancer Cells Against Hypoxia and Drug-Induced Hydrogen Peroxide-Dependent Apoptosis. Molecular Cancer Research 2003, , 1: 682-689.

54. Yavuz BB, Yavuz B, Halil M, Cankurtaran M, Ulger Z, Cankurtaran ES, et al: Serum elevated gamma glutamyltransferase levels may be a marker for oxidative stress in Alzheimer's disease. Int Psychogeriatr 2008, 20:815-23.

55. Spencer JPE, Jenner $P$, Halliwell B: Superoxide-dependent depletion of reduced glutathione by L-DOPA and dopamine: relevance to Parkinson disease. NeuroReport 1995, 6:1480-1484.

56. Atmaca M, Kuloglu M, Tezcan E, Ustundag B: Antioxidant enzyme and malondialdehyde levels in patients with social phobia. Psychiatry Research 2008, 159:95-100.

\section{Pre-publication history}

The pre-publication history for this paper can be accessed here: http://www.biomedcentral.com/1471-2377/11/139/prepub

\section{doi:10.1186/1471-2377-11-139}

Cite this article as: Al-Yafee et al:: Novel metabolic biomarkers related to sulfur-dependent detoxification pathways in autistic patients of Saudi Arabia. BMC Neurology 2011 11:139.

\section{Submit your next manuscript to BioMed Central and take full advantage of:}

- Convenient online submission

- Thorough peer review

- No space constraints or color figure charges

- Immediate publication on acceptance

- Inclusion in PubMed, CAS, Scopus and Google Scholar

- Research which is freely available for redistribution

Submit your manuscript at www.biomedcentral.com/submit
C Biomed Central 